\title{
Age and Outcome in Gastrointestinal Cancers: A Population-Based Evaluation of Oesophageal, Gastric and Colorectal Cancer
}

\author{
Anne Schlesinger-Raab ${ }^{a}$ Jens Werner ${ }^{b}$ Helmut Friess ${ }^{c} \quad$ Dieter Hölzel $^{a} \quad$ Jutta Engel ${ }^{a}$ \\ ${ }^{a}$ Munich Cancer Registry (MCR) of the Munich Cancer Centre (MCC), Institute for Medical Information Processing, \\ Biometry and Epidemiology (IBE), Klinikum der Universität München (KUM), Ludwig-Maximilians-University (LMU), Munich, Germany; \\ ${ }^{b}$ Department of Surgery, Klinikum der Universität München (KUM), Ludwig-Maximilians-University (LMU), Munich, Germany; \\ ${ }^{\mathrm{c}}$ Department of Surgery, Klinikum Rechts der Isar (RDI), Technical University Munich (TUM), Munich, Germany
}

\section{Keywords}

Oesophageal cancer · Gastric cancer - Colorectal cancer . Elderly · Cancer registry

\section{Summary}

Background: With demographic changes and partial representativeness of randomized studies the question arises which results are achieved in the treatment of the elderly. The objective was to analyse population-based data on gastrointestinal cancers in terms of age. Methods: Analyses included data of the Munich Cancer Registry, i.e. $4,014,10,127$ and 42,809 invasive oesophageal, gastric and colorectal cancer patients, respectively, which were diagnosed between 1998 and 2014. Tumour characteristics and outcome were analysed by age groups and therapy. Overall survival was analysed using the KaplanMeier method, and relative survival was computed as estimation for cancer-specific survival. Additionally, conditional survival of patients surviving at least 6 or 12 months was analysed by age. Results: 21,44 and $38 \%$ of oesophageal, gastric and colorectal cancer patients, respectively, were aged $>75$ years. Of these, 15, 46 and $73 \%$ were surgically treated with curative intent, respectively, which is significantly less than in younger patients. The total 5 -year relative survival was 24,33 and $66 \%$, respectively. The differences in median survival by age group were diminished by selecting those surviving at least 6 or 12 months and those with curatively intended treatment. Conclusion: An adequate patient selection for therapies of these gastrointestinal cancers was demonstrated at large. If the patients' general conditions allowed curatively intended treatment, it was applied and led to similar outcomes irrespective of age.

(c) 2017 S. Karger GmbH, Freiburg

\section{Introduction}

In Germany, the absolute numbers of incident cancer cases prognosticated for the year 2016 are 7,200, 15,600 and 61,300 for oesophageal (C15), gastric (C16) and colorectal (C18-20) cancer, with a male/female proportion of 3.5, 1.4 and 1.2, respectively. Whereas C15 incidence and mortality were nearly stable for more than one decade, C16 incidence and mortality have decreased over more than three decades, and since the early 1990s, C18-20 mortality as well as since $2003, \mathrm{C} 18-20$ incidence are decreasing likewise. However, these gastrointestinal cancers are still accountable for $2.0,3.6$ and $13.4 \%$ of new cancer cases in men and $<1,2.9$ and $12.6 \%$ of new cancer cases in women, respectively [1].

Because of their peak incidence in the sixth and seventh decade in men and in the eighth and ninth decade in women [2], the absolute numbers and proportions of older patients with these cancers will increase with the expanding older population in industrial countries $[3,4]$.

Because the only option for cure in gastrointestinal cancers is complete tumour removal, and as the patients' surgical risk increases with age, fulfilling the requirements of adequate treatment will get more difficult for surgery than for other adjuvant treatment options. In times of demographic ageing, prospective randomised clinical trials do not represent the general population just yet. Therefore, their results cannot be extended to the elderly and transferred one-to-one to routine care. As a result, observational population-based cancer registry data offer a chance to fill the information gap due to lack of evidence from randomized controlled trials, to evaluate the advances in cancer therapy, and to examine whether the elderly do benefit from medical advances as well. In this context, it is the goal of comparative effectiveness research to inform clinical decisions between alternate treatment

\section{KARGER}

(c) 2017 S. Karger GmbH, Freiburg

Fax +497614520714
Dr. Anne Schlesinger-Raab

Munich Cancer Registry (MCR) at the Institute for Medical Information Processing, Biometry and Epidemiology (IBE)

Klinikum der Universität München (KUM), Ludwig-Maximilians-University (LMU)

Marchioninistraße 15, 81377 München, Germany

schlesi@ibe.med.uni-muenchen.de 


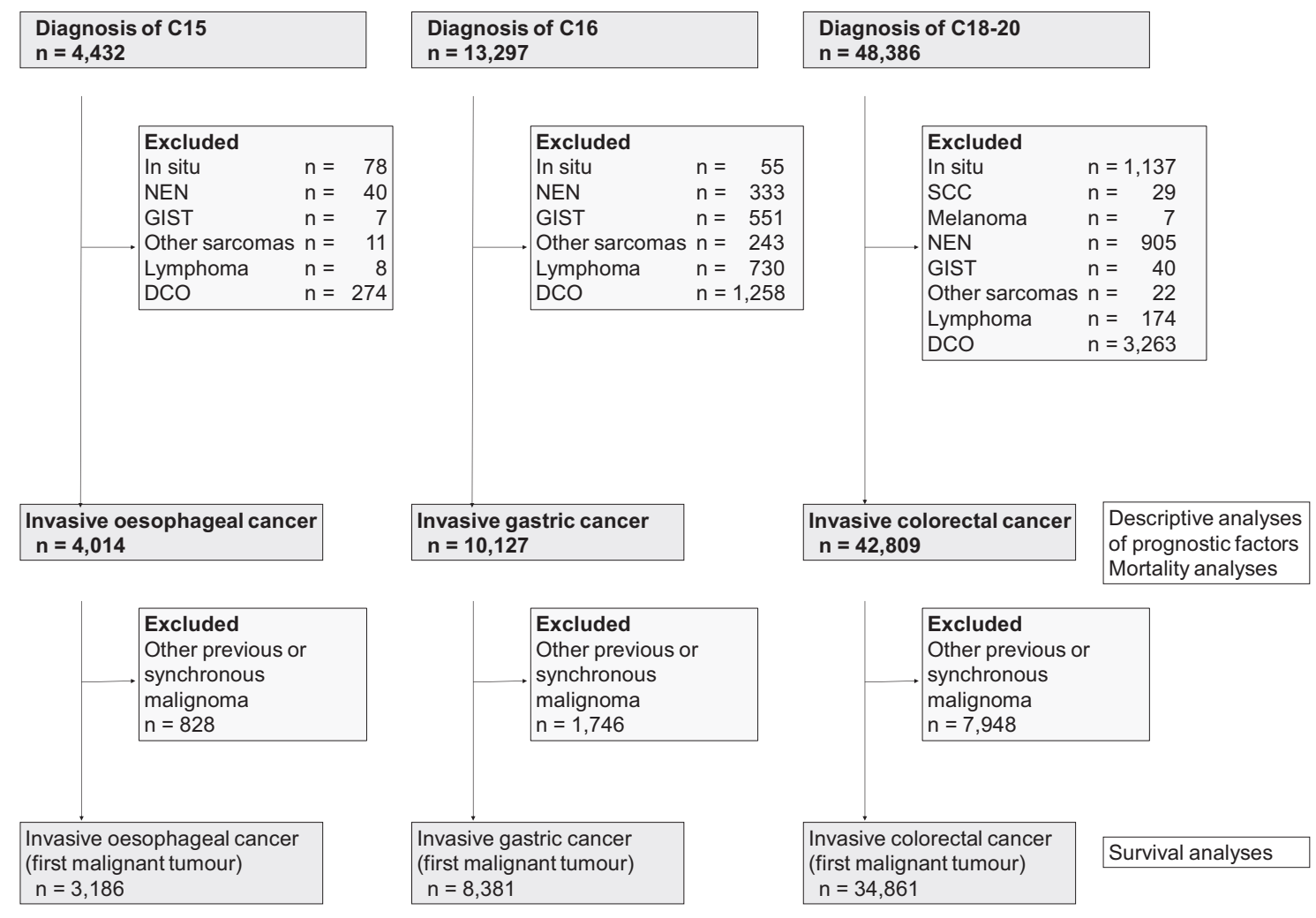

Fig. 1. Cohort profiles of oesophageal, gastric and colorectal cancer cohorts (19982014). (first malignant tumour)

$\mathrm{n}=3,186$

\begin{tabular}{|l|}
\hline Diagnosis of $\mathrm{C} 16$ \\
$\mathrm{n}=13,297$
\end{tabular}

48,386 strategies using data that reflect real patient populations and realworld clinical scenarios for the purpose of improving patient outcomes [5].

Hence, the objective of this study is to survey tumour characteristics, treatments, and outcome of oesophageal, gastric and colorectal cancer by age strata in a German population-based setting.

\section{Material and Methods}

\section{Data Collection}

The Munich Cancer Registry (MCR) is the population-based clinical cancer registry of Upper Bavaria and, partly, of Lower Bavaria (Southern Germany). Its catchment area has been enlarged from 2.3 million inhabitants in 1998 to 4.8 million nowadays. Pathology reports of solid tumours from all pathology laboratories in this catchment area are available. From these reports, the total number of gastrointestinal cancer patients in the region is systematically assessed and the main prognostic factors are ascertained. In parallel, clinicians complete standardised forms concerning the patients' domicile, age, primary disease characteristics such as TNM stage, histology, grade, as well as therapies or deliver these data online to the MCR. Additionally, the life status of patients with a cancer diagnosis is systematically maintained through death certificates. Thus, active follow-up data are available for about $95 \%$ of all cases

\section{Patient Sample}

A total of 4,432 oesophageal, 13,297 gastric and 48,386 colorectal malignant tumour patients with residence in the catchment area were diagnosed between 1998 and 2014 (fig. 1). Patients with a non-invasive carcinoma, neuroendocrine tumour, gastrointestinal stroma tumour, and other sarcoma or lymphoma as well as death certificate only (DCO) cases (6.2, 9.5 and 6.7\%, respectively) were excluded from the analyses. Thus, the analyses of the three epidemiological cohorts of 4,014, 10,127 and 42,809 patients provide a current and population-based survey of invasive oesophageal, gastric and colorectal carcinoma, respectively.
Patients with evidence of another previous or synchronous malignant tumour were excluded from survival analyses to eliminate overlaying tumour effects and treatment restrictions. Thus, the cohorts of the survival analyses comprised $3,186,8,381$ and 34,861 patients. It was assured by preliminary analyses that survival differences between these reduced cohorts and the total cohorts including patients with synchronous and preceding tumours are about 1.5 percent points in colorectal cancer and even smaller in oesophageal and gastric cancer, confirming that the effects of preceding and synchronous other competitive tumours can be neglected.

In order to examine the effects of treatment, a variable 'surgery with curative intent' was generated for each cancer, considering all surgical procedures which are suitable for complete tumour removal, such as oesophagectomy, gastrectomy, and hemicolectomy, or considering the status of tumour residual R0 if other specifications were missing. The extent of lymph node removal was not evaluated.

\section{Statistics}

The MCR organises data in an Oracle database. Statistical analyses were run in SAS (Statistical Analysis System 9.4; SAS Institute, Cary, NC). Frequency data were analysed using the chi-square test. The percentages of the presented subcategories were related to the sum of each item with available data; missing values were not taken into account.

Observed (unadjusted overall) survival was estimated by the Kaplan-Meier method and curves were drawn up to 10 patients at risk. Relative survival was calculated by the ratio of the observed survival rate to the expected survival rate. The expected survival time of age- and sex-matched individuals was calculated using life tables of the general German population. Relative survival can be interpreted as survival from cancer after correction for other causes of death and is therefore used as an estimate for cancer-specific survival. To adjust for effects of age on treatment outcome, such as postoperative mortality, a conditional survival analysis was calculated for those who survived at least half a year in oesophageal and gastric cancer and at least 12 months in colorectal cancer, according to the landmark method proposed by Anderson et al. [6]. These landmarks approximately represent the median survival of the primarily metastasized patients (M1). The significance level $\alpha$ was set at 0.05 in all statistical tests. 
Table 1. Epidemiologic measures in oesophageal, gastric and colorectal cancer

\begin{tabular}{|c|c|c|c|}
\hline & $\begin{array}{l}\text { Oesophageal } \\
\text { cancer }\end{array}$ & Gastric cancer & Colorectal cancer \\
\hline \multicolumn{4}{|l|}{ Incidence male/female } \\
\hline 1998-2014 MCR, per 100,000 and year WS & $5.4 / 1.2$ & $11.0 / 6.1$ & $40.9 / 25.5$ \\
\hline AAPC $2000-2013$ MCR, \% & $-1.7 / \pm 0$ & $-2.5 /-2.9$ & $-2.3 /-2.5$ \\
\hline 2016 Germany, n per year $[1]$ & $5,600 / 1,600$ & $9,200 / 6,400$ & $33,700 / 27,600$ \\
\hline 2009-2013 Germany, per 100,000 and year WS [12] & $6.3 / 1.4$ & $10.8 / 5.7$ & $38.3 / 23.8$ \\
\hline 2009-2013 USA, per 100,000 and year WS [13] & $5.1 / 1.0$ & $5.6 / 2.8$ & $29.0 / 21.8$ \\
\hline AAPC 2004-2013 USA, \% [13] & $-0.7 /-0.6$ & $-1.5 /-0.6$ & $-3.4 /-3.0$ \\
\hline \multicolumn{4}{|l|}{ Age, years } \\
\hline Median male/female MCR & $65.8 / 68.8$ & $71.8 / 76.5$ & $70.1 / 74.1$ \\
\hline 25-/75-percentile MCR & $58.9 / 74.1$ & $63.9 / 73.6$ & $63.1 / 80.1$ \\
\hline \multicolumn{4}{|l|}{ Death certificate only (DCO) cases } \\
\hline Patients MCR, \% & 6.2 & 9.5 & 6.7 \\
\hline Median age of DCO cases MCR, years & 75.2 & 83.7 & 84.0 \\
\hline \multicolumn{4}{|l|}{ Lifetime risk, \% } \\
\hline Germany, age > $65[1]$ & $0.7 / 0.2$ & $1.7 / 1.1$ & $6.3 / 4.9$ \\
\hline USA, age $>60[13]$ & $0.80 / 0.21$ & $0.91 / 0.49$ & $4.1 / 3.7$ \\
\hline \multicolumn{4}{|l|}{ 5-year relative survival, \% } \\
\hline 1998-2006/2007-2014 MCR & $20.1 / 26.6$ & $32.5 / 34.6$ & $66.0 / 65.1$ \\
\hline 1999-2005/2006-2012 USA [13] & $17.6 / 19.2$ & $24.1 / 29.2$ & $66.1 / 65.8$ \\
\hline Europe 2005-2007 [14] & 15.2 & 26.2 & 60.5 \\
\hline
\end{tabular}

Age cut-offs at 65,70 or 75 years are common in the literature [7-11]. Therefore, three age groups $(<60,60-75\rangle$,75 years) were chosen for evaluation. In addition, survival was examined in five age groups $(<50,50-59,60-69,70-79$, $\geq 80$ years) to provide further detailed information about the effects of age. Relative survival in the oldest age group, i.e. $\geq 80$ years, fluctuates more and more with longer follow-up. The expected 1-year survival in this group is lower than $90 \%$. The decreasing absolute patient numbers after the 90th year lead to an instable quotient of observed and expected survival which may even increase.

\section{Results}

\section{Incidence and Survival}

Epidemiologic measures comparing the MCR catchment area, Germany, and the USA are presented in table 1. Overall, the age-adjusted incidences are higher in the German and the MCR population compared to the USA $[12,13]$. The MCR gastric cancer incidence is double in males and 2.2-fold higher in females (11.0 and 6.1 vs. 6.5 and 2.8). The oesophageal cancer incidences are between 20 and $40 \%$ higher in the German population (6.3 and 1.4 vs. 5.1 and 1.0). The colorectal cancer incidence is $40 \%$ higher in MCR males and 17\% higher in MCR females (40.9 and 25.5 vs. 29.0 and 21.8).

The median age in the MCR population is always about 3-4 years higher in females, the youngest in oesophageal cancer $(65.8$ and 68.8 years), and the oldest in gastric cancer (71.8 and 76.5 years).

The lifetime risk to get diagnosed with oesophageal cancer is nearly similar in Germany and the USA, while it is twice as high to get diagnosed with gastric cancer in Germany.
The 5-year relative survival is higher in the MCR population with 20.1 and $26.6 \%$ for males and females with oesophageal cancer compared to 17.6 and $19.2 \%$ in the USA. In gastric cancer, these differences are even higher with 32.5 and $34.6 \%$ compared to 24.1 and $29.2 \%$. In this regard, the DCO rates in the MCR area of 6.2, 9.5 and 6.7\% for oesophageal, gastric and colorectal cancer, respectively, with a median age of DCO cases always above the $75 \%$-percentile should be commemorated. In colorectal cancer, the 5 -year relative survival is nearly the same with 66 and $65.1 \%$ in the area of the MCR and 66.1 and $65.8 \%$ in the USA.

\section{Patient and Tumour Characteristics}

The population-based cohorts of oesophageal, gastric and colorectal cancer comprise 4,014, 10,127 and 42,809 cases from 1998 to 2014 , respectively. Selected patient and tumour characteristics stratified by three age groups are described in table $2-4$.

In all three tumour entities, men are overrepresented, with a slight change towards women in the oldest age group. In general, the younger ( $<60$ years) have higher proportions of primary M1 tumours. In oesophageal and gastric cancer, their tumours show a worse tumour grade (G3). The oesophageal cancers of the elderly (>75 years) are adenocarcinomas in nearly $50 \%$ of cases compared to $35 \%$ in the younger age groups, while the distribution of tumour site and stage is nearly the same in every age group. In general, the proportion of unavailable specifications is always highest in the oldest age group.

In gastric cancer, the younger show higher proportions of tumours of the gastro-oesophageal junction and of signet cell carci- 
Table 2. Oesophageal cancer: selective characteristics by three age groups (epidemiologic cohort 1998$2014, \mathrm{n}=4,014$ )

\begin{tabular}{|c|c|c|c|c|c|}
\hline & \multicolumn{3}{|l|}{ Age, years } & \multirow[t]{2}{*}{ Total } & \multirow[t]{2}{*}{$\mathrm{p}$-value } \\
\hline & $<60$ & $60-75$ & $>75$ & & \\
\hline Oesophageal cancer, n (\%) & $1,155(28.8)$ & $2,013(50.2)$ & $846(21.1)$ & $4,014(100)^{\mathrm{a}}$ & \\
\hline Male/female, \% & $82.7 / 17.3$ & $80.5 / 19.5$ & $72.1 / 27.9$ & $79.4 / 20.6$ & $<0.0001$ \\
\hline Grade 3, \% & 52.1 & 49.1 & 45.8 & 49.3 & $<0.0001$ \\
\hline c/p UICC Stage, \% & & & & & $<0.0001$ \\
\hline I & 6.5 & 7.1 & 5.1 & 6.5 & \\
\hline II & 10.6 & 10.7 & 7.8 & 10.0 & \\
\hline III & 28.2 & 29.1 & 21.8 & 27.3 & \\
\hline IV & 25.5 & 23.1 & 18.0 & 22.7 & \\
\hline Stage not available/M0 & 29.2 & 30.1 & 47.4 & 33.5 & \\
\hline Histology, $\%^{\mathrm{b}}$ & & & & & $<0.0001$ \\
\hline Squamous cell carcinoma & 64.2 & 62.8 & 48.5 & 60.2 & \\
\hline Adenocarcinoma & 34.0 & 35.4 & 49.0 & 37.8 & \\
\hline Other carcinomas & 1.8 & 1.8 & 2.7 & 2.0 & \\
\hline Not available & 1.6 & 1.8 & 3.2 & 2.0 & \\
\hline \multicolumn{5}{|c|}{ Tumour site, \%/proportion adenocarcinoma, \% } & $<0.0001$ \\
\hline Upper third & $13.9 / 3.1$ & $12.4 / 2.4$ & $9.8 / 4.8$ & $12.3 / 3.0$ & \\
\hline Middle third & $19.9 / 6.5$ & $20.8 / 5.7$ & $16.9 / 22.4$ & $19.7 / 9.0$ & \\
\hline Lower third & $51.3 / 56.4$ & $50.2 / 57.9$ & $51.0 / 69.1$ & $50.7 / 59.9$ & \\
\hline NOS & $15.0 / 19.1$ & $16.6 / 25.1$ & $22.3 / 35.4$ & $17.3 / 26.4$ & \\
\hline \multicolumn{6}{|l|}{ Therapy, \% } \\
\hline Surgery with curative intent & 36.4 & 27.2 & 14.8 & 27.2 & $<0.0001$ \\
\hline \multicolumn{6}{|l|}{ Life status, $\%$} \\
\hline Deceased within 1 year & 40.2 & 46.9 & 58.9 & 47.5 & $<0.0001$ \\
\hline \multicolumn{6}{|c|}{$\begin{array}{l}{ }^{\text {a }} \text { Row and column percentages can differ slightly from } 100 \% \text { due to rounding. } \\
\text { b Missing values were excluded from calculations of frequency distribution. } \\
\text { NOS = Not otherwise specified. }\end{array}$} \\
\hline
\end{tabular}

noma. Similarly, the stage distribution does not substantially differ by age.

In colorectal cancer, the oldest age group ( $>75$ years) comprises more women than men as well as less rectal cancers ( 28.9 vs. $44.3 \%$ in the youngest age group).

\section{Therapy}

Information on surgery with curative intent differs strongly: it is least, i.e. $27.2 \%$, in oesophageal cancer, $57 \%$ in gastric cancer, and $78.8 \%$ in colorectal cancer. In all tumour entities it is shown that the proportion of patients treated with surgical procedures with curative intent decreases with higher age. In colorectal cancer, the guideline-recommended adjuvant and neoadjuvant treatments are cautiously carried out in the oldest age group. Primarily, the proportion of 'stage not available' is attributable to the non-surgically treated patients.

\section{Survival}

Overall (or observed), relative, expected survival and relative survival in two periods of diagnosis (1998-2006, 2007-2014) as well as comparative SEER data are presented in fig. $2 \mathrm{a}-\mathrm{c}$. The different curves of expected survival reflect the different age distribu- tion of each cancer. Patients with oesophageal cancer are the relatively youngest, so their expected survival is higher compared to that of gastric cancer patients who are the oldest. Fig. $2 \mathrm{~d}-\mathrm{f}$ shows that the worsening prognostic effect of age is seen in patients of 70 years and older in all tumour entities.

\section{Oesophageal Cancer}

The 5 -year relative survival is $24 \%$. There has been a slight survival improvement over the two time periods with a median survival of 11 months in the period of 1998-2006 and of 16 months in the period of 2007-2014 (fig. 2a). The median survival worsens continuously with increasing age: it is 1.5 years in the youngest age group ( $<50$ years) and 6 months in the oldest ( $\geq 80$ years). The difference between overall and relative survival in the first year from initial diagnosis is very low in every age group, indicating that nearly all patients die of their cancer (fig. $2 \mathrm{~d}$ ). The 5-year relative survival is $31.3,26.0,25.2,21.9$ and $13.0 \%$ in the five age groups. The condition of having survived at least 6 months slightly reduces these differences in 5-year relative survival $(38.8,32.2,37.5,31.4$ and $26.3 \%$, as shown in fig. $2 \mathrm{~g}$ ). Relative survival by age and tumour stage is presented in fig. 3a: in the most advanced stage IV, the age has no substantial effects, with an observed median survival 
Table 3. Gastric cancer: selective characteristics by three age groups (epidemiologic cohort 1998-2014, $\mathrm{n}=10,127$ )
Table 4. Colorectal cancer: selective characteristics by three age groups (epidemiologic cohort 1998-2014, $\mathrm{n}=42,809$ )

\begin{tabular}{|c|c|c|c|c|c|}
\hline & \multicolumn{3}{|l|}{ Age, years } & \multirow[t]{2}{*}{ Total } & \multirow[t]{2}{*}{$\mathrm{p}$-value } \\
\hline & $<60$ & $60-75$ & $>75$ & & \\
\hline Gastric cancer, n (\%) & $1,851(18.3)$ & $3,787(37.4)$ & $4,489(44.3)$ & $10,127(100)^{\mathrm{a}}$ & \\
\hline Male/female, $\%$ & $61.9 / 38.1$ & $63.5 / 36.5$ & $49.4 / 50.6$ & $57.0 / 43.0$ & $<0.0001$ \\
\hline Grade 3, \% & 80.1 & 67.6 & 61.6 & 67.3 & $<0.0001$ \\
\hline GEJ, \% & 25.0 & 21.9 & 17.6 & 20.7 & $<0.0001$ \\
\hline c/p UICC Stage, $\%^{b}$ & & & & & $<0.0001$ \\
\hline I & 22.2 & 25.1 & 18.9 & 21.8 & \\
\hline II & 16.3 & 13.4 & 10.4 & 12.6 & \\
\hline III & 13.1 & 12.4 & 10.9 & 11.9 & \\
\hline IV/M0 & 5.4 & 5.2 & 3.2 & 4.4 & \\
\hline IV/M1 & 32.5 & 29.9 & 20.7 & 26.3 & \\
\hline Stage not available/M0 & 10.5 & 13.9 & 35.8 & 23.0 & \\
\hline Histology, \% & & & & & $<0.0001$ \\
\hline Adenocarcinoma & 57.5 & 71.9 & 79.8 & 72.8 & \\
\hline Signet cell carcinoma & 40.0 & 25.9 & 17.3 & 24.7 & \\
\hline Other carcinomas & 2.6 & 2.2 & 2.9 & 2.6 & \\
\hline Not available & 1.4 & 1.7 & 2.2 & 1.9 & \\
\hline \multicolumn{6}{|l|}{ Therapy, \% } \\
\hline Surgery with curative intent & 68.5 & 63.9 & 46.3 & 57.0 & $<0.0001$ \\
\hline \multicolumn{6}{|l|}{ Life status, \% } \\
\hline Deceased within 1 year & 29.6 & 37.2 & 56.5 & 44.4 & $<0.0001$ \\
\hline
\end{tabular}

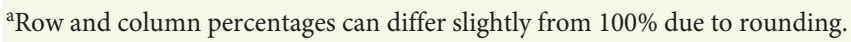
${ }^{\mathrm{b}}$ Missing values were excluded from calculations of frequency distribution. GEJ = Gastro-oesophageal junction.

\begin{tabular}{|c|c|c|c|c|c|}
\hline & \multicolumn{3}{|l|}{ Age, years } & \multirow[t]{2}{*}{ Total } & \multirow[t]{2}{*}{$\mathrm{p}$-value } \\
\hline & $<60$ & $60-75$ & $>75$ & & \\
\hline Colorectal cancer, n (\%) & $8,031(18.8)$ & $18579(43.4)$ & $16,199(37.8)$ & $42809(100)^{\mathrm{a}}$ & \\
\hline Male/female, \% & $58.3 / 41.7$ & $62.6 / 37.4$ & $46.0 / 54.0$ & $55.5 / 44.5$ & $<0.0001$ \\
\hline Grade 3, \% & 23.4 & 21.4 & 23.4 & 22.5 & $<0.0001$ \\
\hline Rectal cancer, \% & 44.3 & 37.7 & 28.9 & 35.6 & $<0.0001$ \\
\hline c/p UICC Stage, $\%$ b & & & & & $<0.0001$ \\
\hline I & 18.3 & 20.8 & 16.3 & 18.6 & \\
\hline II & 21.9 & 25.2 & 28.4 & 25.8 & \\
\hline III & 28.7 & 25.7 & 23.5 & 25.4 & \\
\hline IV & 23.0 & 19.5 & 18.3 & 19.7 & \\
\hline Stage not available/M0 & 8.1 & 8.8 & 13.5 & 10.4 & \\
\hline \multicolumn{6}{|l|}{ Therapy, \% } \\
\hline Surgery with curative intent & 83.3 & 81.6 & 73.2 & 78.8 & $<0.0001$ \\
\hline \multicolumn{6}{|l|}{ Life status, \% } \\
\hline Deceased within 1 year & 8.9 & 13.8 & 30.0 & 19.0 & $<0.0001$ \\
\hline
\end{tabular}



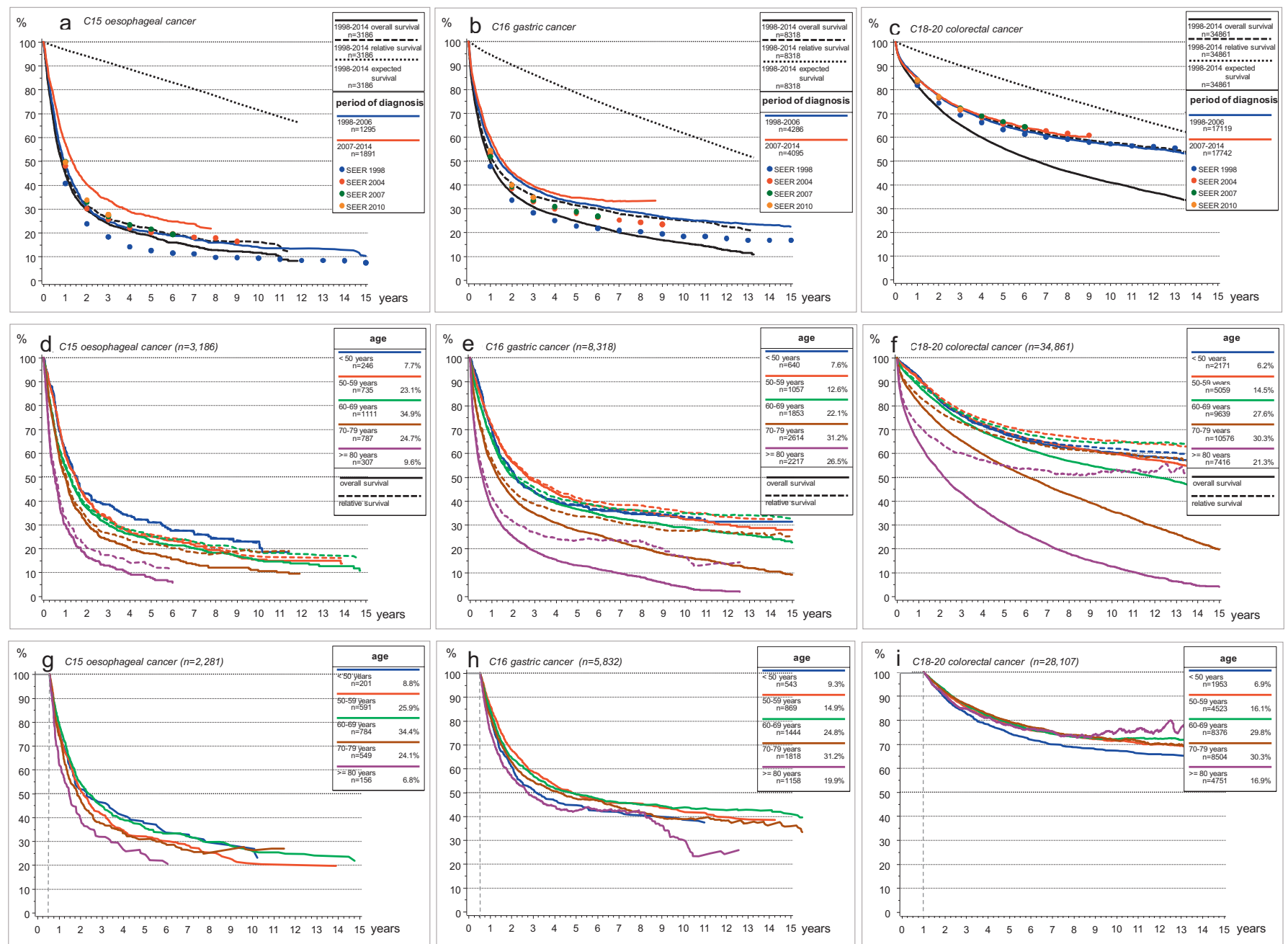

Fig. 2. a-c Overall, relative and expected survival, relative survival by period of diagnosis and tumour, $\mathbf{d - f}$ relative survival by age and tumour, and $\mathbf{g - i}$ conditional relative survival for those who have survived at least 6 months in C15 and C16 and at least 12 months in C18-20.

of 7 months in those $<60$ years and less than 4 months in those $>75$ years. In stage III, those $>75$ years have a slightly worse prognosis with a median survival of 11 months compared to 18 months for the younger age groups. Fig. $3 d$ presents the relative survival stratified by age and therapy. Here, it is shown that the adequate surgical therapy - if applicable- overlies the effects of age.

\section{Gastric Cancer}

The 5-year relative survival is $33.4 \%$, and there may be an improvement for those who survive at least 5 years (fig. 2b). As in oesophageal cancer, death in the first year after diagnosis is completely due to cancer. Stratified by age, the median survival is between 7 months and 2.7 years. The 5 -year relative survival differs between $41.2 \%$ in the age group of $50-59$ years and $23.5 \%$ in those $\geq 80$ years (fig. 2e). Again, for those who have survived at least 6 months the effects of age are diminished (fig. 2h). Fig. 3b demonstrates the by far worst prognosis of the elderly $>75$ years irrespective of tumour stage. Fig. 3e underlines the desperate outcome of those without feasible adequate surgery with a median survival below 1 year irrespective of age.

\section{Colorectal Cancer}

The 5-year relative survival is $65.6 \%$, and substantial improvements since 1998 cannot be seen in the total cohort (fig. 2c). The better prognosis of colorectal cancer leads to stronger effects of age. Overall and relative survival divide after 6 months, and relative median survival is not yet reached in all age groups after 15 years of observation (fig. 2f). The conditional relative survival of those who survived at least 1 year is nearly the same in all age groups of 50 years and older. Only the youngest, i.e. $<50$ years, have a slightly worse prognosis (fig. 2i). Fig. 3 c shows that only the oldest, i.e. $\geq 80$ years, do not similarly benefit from adequate surgical treatment as those younger than 80 years.

\section{Post-Progression Survival from First Distant Metastasis}

Fig. 3g-i demonstrates the impact of age on post-progression survival after first distant metastasis which strengthens with improved prognosis: in oesophageal cancer with the worst prognosis, the median survival of the youngest is 2.3 -fold longer than that of the oldest, in gastric cancer it is 2.7 -fold longer, and in colorectal cancer it is 4.2 -fold longer. 

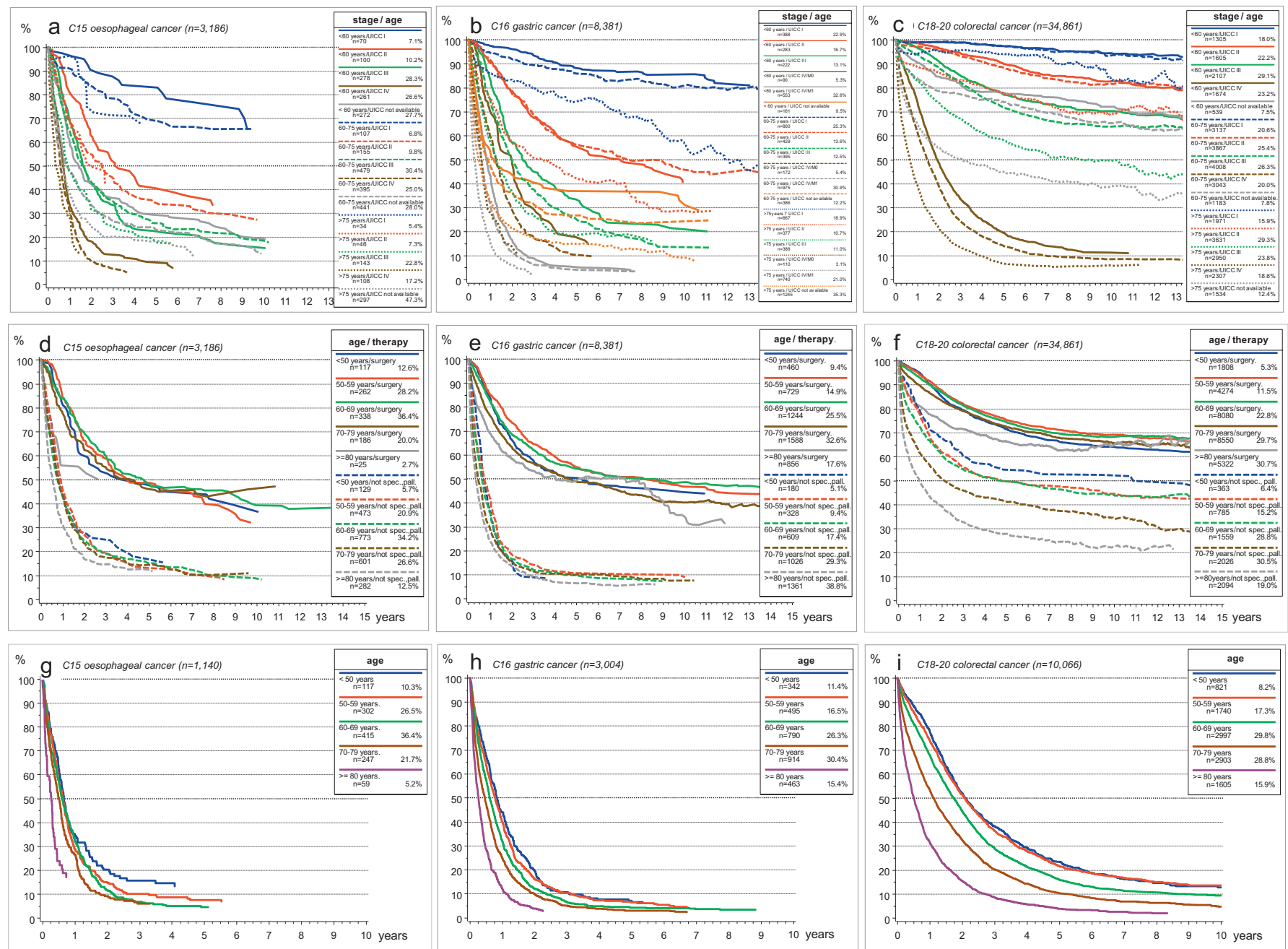

Fig. 3. Relative survival by a-c stage, age, and tumour as well as by $\mathbf{d - f}$ age, therapy, and tumour and $\mathbf{g - i}$ post-progression survival by age and tumour.

\section{Discussion}

The age-standardised incidences of oesophageal cancer in males and of gastric and colorectal cancers in general have continuously decreased. In oesophageal cancer, this is likely to reflect the decreasing tobacco consume and runs parallel to the decrease of male lung cancer incidence. In colorectal cancer, the establishment of screening could perhaps show its effects.

Absolutely, however, numbers have not decreased because of the increasing age of cancer patients, especially in oesophageal and colorectal cancer $[2,14]$. This bears challenges for all health care providers, particularly for the fields of surgery, oncology, and radiotherapy.

The choice of any more or less invasive treatment does mostly depend on tumour prognosis and the patients' general condition which is strongly related to age, besides lifestyle factors such as alcohol and tobacco abuse which can be seen more often in oesophageal cancer patients. Therefore, aged patients above 75 years are rightly underrepresented in the curatively treated groups, with the lowest proportion in oesophageal cancer with $15 \%$ and the highest in colorectal cancer with $73 \%$.
The survival analyses show an improvement of relative survival over two time periods similar to SEER data in oesophageal cancer. In oesophageal cancer, this may be explained by a shift to $15 \%$ more adenocarcinoma since 1998 and to localisation in the lower oesophagus, thus yielding a better prognosis than squamous cell carcinoma of the middle and upper parts. Essential improvements of survival in the first 6 months due to a quantum leap in treatment are not seen. The major advances in colorectal cancer treatment were presented with fluorouracil-based chemotherapy and total mesorectal excision in the late 1980s and 1990s and with neoadjuvant radiochemotherapy in locally advanced rectal cancer in the early 2000 s [15-18]. While patients were on average 2 years older in the latter time period, one may state a further minor improvement.

Because age, frailty, and sarcopenia are associated with risk of perioperative morbidity and mortality in gastrointestinal cancers, the survival differences of age groups are explained [19, 20]. However, there is evidence that minimally invasive techniques can be safely performed with functional and oncological equivalent in older colorectal cancer patients and may be an option for gastric cancer therapy in the near future $[21,22]$. 
Remarkable is the survival of those patients who were treated with surgery appropriate for complete tumour removal and cure. In gastric cancer, the 5-year relative survival differs by age between 55 and $50 \%$. This small difference argues for a reliable indication for surgery, because $71 \%$ of those $<50$ years and $39 \%$ of those $\geq 80$ years are treated in this way with almost similar results. If an essentially greater proportion of the elderly was treated in this way, the survival would be worse because of greater postoperative morbidity and mortality. If the indication for surgery was improved by excluding the very early deceased patients, the survival of the patients treated surgically with curative intent would further improve. This can also be seen in the conditional survival of colorectal cancer patients where the exclusion of those who survive 1 year at most leads to an improved survival of more than $5 \%$, also for the oldest. Thus, in all cancers the challenge is posed to identify those with an unfavourable prognosis of a few months and to apply less invasive therapies.

We acknowledge several limitations of this study which must be considered in the interpretation of the results. The study is a cohort study with all the well-established drawbacks. A DCO rate of more than $5 \%$ as well as DCO patients who are in median 10 years older than the non-DCO cases and also missing values may mask selections. Complementary data to the conducted treatments with decided information on deliberately not conducted or not indicated treatments would be desirable. This also applies to comorbidities or desperate prognosis which do not allow the implementation of a recommended therapy, even if such data could not be permanently collected in a population-specific and valid manner for all therapies in a cancer registry. Despite these drawbacks, the presented results on the age dependency of treatment seem valid because of their plausibility, the marginal variability between hospitals, and missing contradictions in comparison to the literature [23-25].

\section{Conclusion}

Hence, it can be stated that the substandard implementation of curatively intended surgical procedures in the treatment of elderly patient cohorts need not be a sign of deficiency in health care but a sign for reasonable considerations of tumour prognosis, patients' life expectancy, and calendrical and physical age. Current guidelines and established tumour boards, which have been available in recent years, may also have contributed to a reliable health care, a low inter-hospital variability, and a stable long-term survival. The treatment and care of oesophageal, gastric and colorectal cancer in elderly patients seem to be balanced and appropriate in the efforts to discriminate between those who benefit from forced invasive therapies and those who do not. At least, the oldest who are treated in curative intent present similar outcomes as their younger fellow sufferers.

\section{Funding}

The Munich Cancer Registry (MCR) is part of the Munich Tumour Centre (TZM), the Institute for Medical Information Processing, Biometry, and Epidemiology (IBE), the Ludwig-Maximilians-Universität (LMU), and the University Hospital of Munich (KUM).

\section{Acknowledgement}

We thank all the hospitals, departments, and practitioners that participated in the documentation of the data.

\section{Disclosure Statement}

The authors indicated no potential conflicts of interest.

\section{References}

1 Robert Koch Institute; Association of PopulationBased Cancer Registries in Germany (eds): Cancer in Germany 2011/2012, ed 10. Berlin, RKI/GEKID, 2016.

2 Munich Cancer Registry: Cancer-specific analyses basic statistics and survival, 2016. https://www.tumorregister-muenchen.de/en/facts/specific_analysis.php.

3 Nashimoto A: Current status of treatment strategy for elderly patients with gastric cancer. Int J Clin Oncol 2013;18:969-970.

4 Endo S, Dousei T, Yoshikawa Y, Hatanaka N, Kamiike W, Nishijima J: Prognosis of gastric carcinoma patients aged 85 years or older who underwent surgery or who received best supportive care only. Int J Clin Oncol 2013;18:1014-1019.

5 Hershman DL, Wright JD: Comparative effectiveness research in oncology methodology: observational data. J Clin Oncol 2012;30:4215-4222.

6 Anderson JR, Cain KC, Gelber RD: Analysis of survival by tumor response. J Clin Oncol 1983;1:710-719.

7 Gillison TL, Chatta GS: Cancer chemotherapy in the elderly patient. Oncology (Williston Park, NY) 2010; 24:76-85.
8 Dudeja V, Habermann EB, Zhong W, Tuttle TM, Vickers SM, Jensen EH, Al-Refaie WB: Guideline recommended gastric cancer care in the elderly: insights into the applicability of cancer trials to real world. Ann Surg Oncol 2011;18:26-33.

9 Gretschel S, Estevez-Schwarz L, Hunerbein M, Schneider U, Schlag PM: Gastric cancer surgery in elderly patients. World J Surg 2006;30:1468-1474.

10 Biondi A, Cananzi FC, Persiani R, Papa V, Degiuli M, Doglietto GB, D'Ugo D: The road to curative surgery in gastric cancer treatment: a different path in the elderly? J Am Coll Surg 2012;215:858-867.

11 Li Destri G, Cavallaro M, Trovato MA, Ferlito F, Castaing M, Puleo S: Colorectal cancer treatment and follow-up in the elderly: an inexplicably different approach. Int Surg 2012;97:219-223.

12 Robert Koch Institute: Database query, 2017. $w w w$. krebsdaten.de/Krebs/EN/Database/databasequery step1_node.html.
13 Howlader N, Noone A, Krapcho M, Miller D, Bishop K, Altekruse S, Kosary C, Yu M, Ruhl J, Tatalovich Z, Mariotto A, Lewis D, Chen H, Feuer E, Cronin KA (eds): SEER Cancer Statistics Review, 1975-2013. Bethesda, MD, National Cancer Institute, 2015/2016. https://seer.cancer.gov/archive/csr/1975_2013/.

14 Ferlay J, Steliarova-Foucher E, Lortet-Tieulent J, Rosso S, Coebergh JW, Comber H, Forman D, Bray F: Cancer incidence and mortality patterns in Europe: estimates for 40 countries in 2012. Eur J Cancer 2013;49:13741403

15 Heald RJ: The 'Holy Plane' of rectal surgery. J R Soc Med 1988;81:503-508.

16 O'Connell MJ, Martenson JA, Wieand HS, Krook JE, Macdonald JS, Haller DG, Mayer RJ, Gunderson LL, Rich TA: Improving adjuvant therapy for rectal cancer by combining protracted-infusion fluorouracil with radiation therapy after curative surgery. $\mathrm{N}$ Engl J Med 1994;331:502-507.

17 Palliative chemotherapy for advanced or metastatic colorectal cancer. Colorectal Meta-analysis Collaboration. Cochrane Datebase Syst Rev 2000;(2):CD001545. 
18 Kapiteijn E, Marijnen CA, Nagtegaal ID, Putter H, Steup WH, Wiggers T, Rutten HJ, Pahlman L, Glimelius B, van Krieken JH, Leer JW, van de Velde CJ: Preoperative radiotherapy combined with total mesorectal excision for resectable rectal cancer. N Engl J Med 2001;345:638-646.

19 Fagard K, Leonard S, Deschodt M, Devriendt E, Wolthuis A, Prenen H, Flamaing J, Milisen K, Wildiers $\mathrm{H}$, Kenis C: The impact of frailty on postoperative outcomes in individuals aged 65 and over undergoing elective surgery for colorectal cancer: a systematic review. J Geriatr Oncol 2016;7:479-491.

20 Wagner D, DeMarco MM, Amini N, Buttner S, Segev D, Gani F, Pawlik TM: Role of frailty and sarcopenia in predicting outcomes among patients undergoing gastrointestinal surgery. World J Gastrointest Surg 2016; 8:27-40.
21 Biondi A, Vacante M, Ambrosino I, Cristaldi E, Pietrapertosa G, Basile F: Role of surgery for colorectal cancer in the elderly. World J Gastrointest Surg 2016;8: 606-613.

22 Tsai SH, Liu CA, Huang KH, Lan YT, Chen MH, Chao Y, Lo SS, Li AF, Wu CW, Chiou SH, Yang MH, Shyr YM, Fang WL: Advances in laparoscopic and robotic gastrectomy for gastric cancer. Pathol Oncol Res 2017; 23:13-17.

23 Schlesinger-Raab A, Mihaljevic AL, Egert S, Emeny RT, Jauch KW, Kleeff J, Novotny A, Nussler NC, Rottmann M, Schepp W, Schmitt W, Schubert-Fritschle G, Weber B, Schuhmacher C, Engel J: Level of hospital care and outcome of gastric cancer: a population-based evaluation of the Munich Cancer Registry. J Cancer Res Clin Oncol 2014;140:789-800.
24 Dutch Snapshot Research Group: Benchmarking recent national practice in rectal cancer treatment with landmark randomised controlled trials. Colorectal Dis 2017;19:O219-O231.

25 Koppert LB, Lemmens VE, Coebergh JW, Steyerberg EW, Wijnhoven BP, Tilanus HW, Janssen-Heijnen ML: Impact of age and co-morbidity on surgical resection rate and survival in patients with oesophageal and gastric cancer. Br J Surg 2012;99:1693-1700. 